\title{
Effect of Electron Beam Irradiation on Optical Properties of Manganese Tungstate Nanoparticles
}

\author{
K. P. Priyanka, ${ }^{1}$ N. Aloysius Sabu, ${ }^{1}$ Anu Tresa Sunny, \\ P. A. Sheena, ${ }^{3}$ and Thomas Varghese ${ }^{1}$ \\ ${ }^{1}$ Department of Physics, Nanoscience Research Centre (NSRC), Nirmala College, Muvattupuzha, Kerala 686 661, India \\ ${ }^{2}$ School of Chemical Sciences, M.G. University, Kottayam 686560, India \\ ${ }^{3}$ M.E.S. Asmabi College, P. Vemballur, Kerala 680671, India \\ Correspondence should be addressed to Thomas Varghese; nanoncm@gmail.com
}

Received 2 May 2013; Revised 20 June 2013; Accepted 25 June 2013

Academic Editor: Mahi R. Singh

Copyright (C) 2013 K. P. Priyanka et al. This is an open access article distributed under the Creative Commons Attribution License, which permits unrestricted use, distribution, and reproduction in any medium, provided the original work is properly cited.

\begin{abstract}
Manganese tungstate $\left(\mathrm{MnWO}_{4}\right)$ nanoparticles were synthesized at room temperature by chemical precipitation method. The effect of high energy electron beam (EB) irradiation on the optical properties of $\mathrm{MnWO}_{4}$ nanoparticles was investigated. The absorption spectra, photoluminescence intensity, and Raman bands of the irradiated samples were modified, which has been attributed to defects and particle size variation. The present investigation found that the beam irradiation is a new and efficient method to enhance the optical absorption performance and photoactivity of $\mathrm{MnWO}_{4}$ nanoparticles.
\end{abstract}

\section{Introduction}

Nanostructured tungstate materials have aroused much interest because of their luminescence behaviour, structural properties, and potential applications. $\mathrm{MnWO}_{4}$ has bulk electrical conductivity, relatively low melting point, novel magnetic property, and photocatalytic property $[1,2]$. The optical and luminescence properties of $\mathrm{MnWO}_{4}$ have received great attention as they are widely used as scintillating detectors in high-energy particle physics, rare-event searches, and medical diagnosis [3]. The electrical conductivity of $\mathrm{MnWO}_{4}$ is also sensitive to changes in humidity, thereby making it useful as a humidity sensor with potential applications like meteorology, medicine, food production, agriculture, and industrial and domestic environment $[4,5]$. There are a number of processes used to synthesize nanocrystalline $\mathrm{MnWO}_{4}$, such as microwave-assisted synthesis [1], surfactant-assisted complexation-precipitation method [2], melt solution process [6], solvothermal route [7], aqueous salt metathesis reaction [8], sol-gel technique [4, 9], ambient template synthesis [10], and solid state metathetic approach [11].

In the present work, manganese tungstate nanoparticles are synthesized by careful control of the reaction kinetics of aqueous precipitation. As-prepared $\mathrm{MnWO}_{4}$ nanoparticles are characterized by X-ray diffraction [XRD], transmission electron microscopy [TEM], UV-Visible absorption spectroscopy, photoluminescence [PL] spectroscopy and Raman spectroscopy. In addition, the optical properties of the pure and EB irradiated samples of $\mathrm{MnWO}_{4}$ nanoparticles were evaluated in context of the band gap.

\section{Experimental Details}

Manganese chloride $\left(\mathrm{MnCl}_{2} \cdot 4 \mathrm{H}_{2} \mathrm{O}\right)(99.8 \%$, Sigma Aldrich) and sodium tungstate $\left(\mathrm{Na}_{2} \mathrm{WO}_{4} \cdot 2 \mathrm{H}_{2} \mathrm{O}\right)(99.9 \%$, Alfa Aesar) were used without further purification for the synthesis of $\mathrm{MnWO}_{4}$. Distilled water was used in all synthesis procedures.

2.1. Preparation of the Samples. The synthesis procedures for the preparation of $\mathrm{MnWO}_{4}$ nanoparticles used in this work has been described elsewhere [12]. Nanocrystalline manganese tungstate samples were prepared by reacting aqueous solutions of manganese chloride and sodium tungstate $(0.1 \mathrm{M}$ each) at room temperature, keeping the $\mathrm{pH}=7$. The precipitate formed was centrifuged, filtered, washed with distilled water a number of times, and dried in an oven to get 


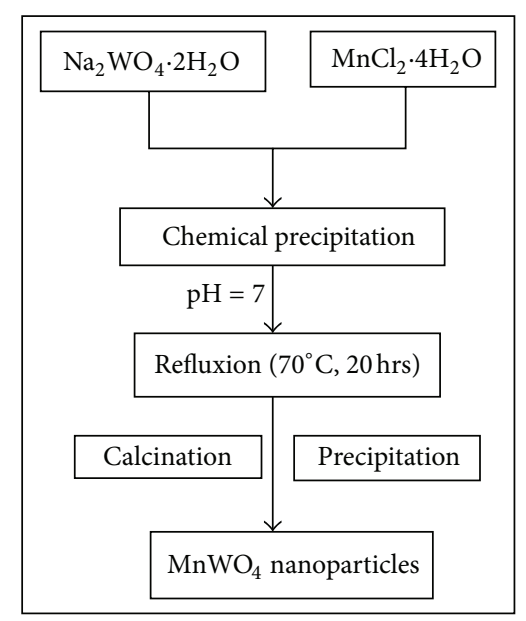

Figure 1: The scheme of preparation of $\mathrm{MnWO}_{4}$ nanoparticles by chemical precipitation method.

fine powders of manganese tungstate. The obtained powder samples were calcined for 3 hours in a furnace at $450^{\circ} \mathrm{C}$ in an aerobic atmosphere. The flow chart showing the scheme of preparation of nanocrystalline $\mathrm{MnWO}_{4}$ is shown in Figure 1.

The $\mathrm{MnWO}_{4}$ samples were taken in microtubes and exposed to EB irradiation at a distance of $30 \mathrm{~cm}$ from the beam exit port. The samples were irradiated at a dose rate of $5 \mathrm{kGy}$ and $10 \mathrm{kGy}$ with an electron beam of $8 \mathrm{MeV}$ energy obtained from a variable energy Microtron at Mangalore University, India. S1 is pure sample of $\mathrm{MnWO}_{4} ; \mathrm{S} 2$ and S3 are irradiated samples with dose rates of $5 \mathrm{kGy}$ and $10 \mathrm{kGy}$, respectively. The samples made significant modifications on their physical properties due to beam irradiation.

\subsection{Characterization. The structural characteristics of the} pure and irradiated manganese tungstate nanoparticles were studied by X-ray powder diffraction using Bruker D8 Advance X-ray diffractometer $(\lambda=1.5406 \AA)$ with $\mathrm{CuK} \alpha$ radiation in $2 \theta$ range from $20^{\circ}$ to $70^{\circ}$. From the XRD analysis all the peaks of $\mathrm{MnWO}_{4}$ were well matched with the Xray pattern of JCPDS Card no. 80-0135. These analyses were carried out for the identification of the crystal phase and the estimation of the average crystallite size. The latter value was estimated from the Debye-Scherrer equation [9]. The DebyeScherrer equation is given by

$$
t=\frac{0.9 \lambda}{\beta \cos \theta},
$$

where $\lambda$ is the $\mathrm{X}$-ray wavelength, $\beta$ is the full width at halfmaximum (FWHM) of the peak, and $\theta$ is the Bragg's angle.

Transmission electron microscopy is a unique tool to get a direct image of the nanoparticles, revealing the distribution in the nanocrystal and on its surface. High magnification imaging with lattice contrast allows the determination of individual crystal morphology. For TEM studies, the $\mathrm{MnWO}_{4}$ powder was dispersed in ethanol using an ultrasonic bath. A drop of the suspension was placed on a copper grid coated with carbon film. After drying, the copper grid containing the nanoparticles was placed on a holder for the imaging process.

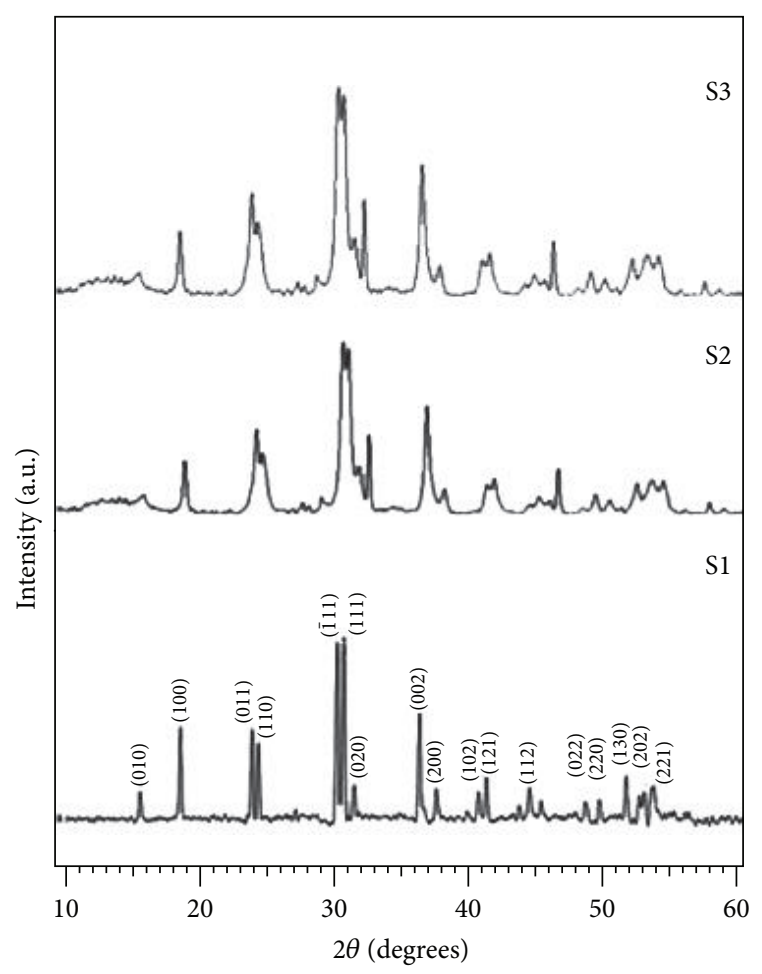

FIGURE 2: XRD spectra of $\mathrm{MnWO}_{4}$ samples.

TEM photographs of the pure nanocrystalline $\mathrm{MnWO}_{4}$ powder samples were taken using a Tecnai 30 G2 Stwin (model), FEI make $300 \mathrm{KV}$ High Resolution Transmission Electron Microscope (HRTEM).

The absorption spectra of the pure and irradiated samples in the range of $200-800 \mathrm{~nm}$ were recorded using a double beam UV-Visible Spectrophotometer (UV 2600 model, Shimadzu). For measurement, the nanoparticles were pressed into a thick pellet and placed at the entrance port of the integrating sphere using a sample holder. Calibration of the absorbance scale was done using standard reference materials.

Photoluminescence spectroscopy is an effective way to investigate the electronic structure and optical characteristics of nanomaterials. This analytical technique reveals information such as surface defects and oxygen vacancies as well as the separation and recombination of photo-induced charge carriers [13]. PL spectra of the pure and EB irradiated samples of $\mathrm{MnWO}_{4}$ were measured at room temperature by a Fluoromax3 Spectrophotometer.

Raman spectroscopy is a powerful tool for the investigation of the structural properties of nanoparticles because the variations in Raman spectra with decreases in particle size can be easily detected. Raman spectra of the pure and irradiated samples of $\mathrm{MnWO}_{4}$ were obtained at room temperature using a Bruker FRA 106/S Raman spectrometer with excitation line of $785 \mathrm{~nm}$.

\section{Results and Discussion}

Figure 2 shows the powder X-ray diffraction patterns of pure and $\mathrm{EB}$ irradiated samples of $\mathrm{MnWO}_{4}$ nanoparticles. From 


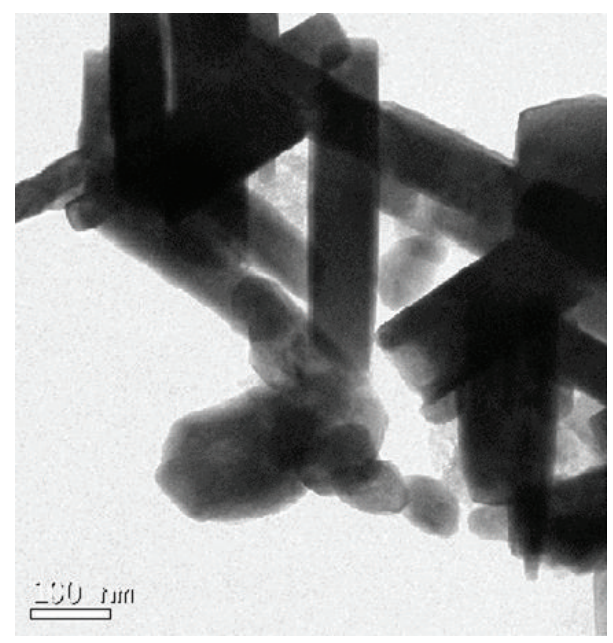

(a)

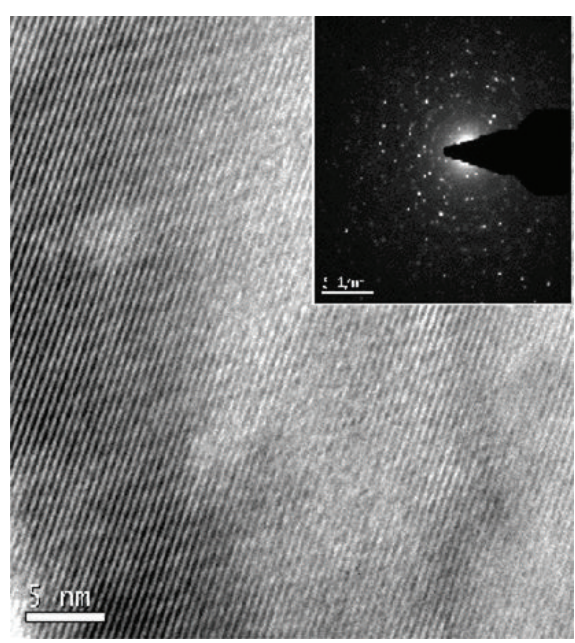

(b)

Figure 3: TEM images of $\mathrm{MnWO}_{4}$ nanoparticles calcined at $450^{\circ} \mathrm{C}$.

XRD patterns, the average particle size of the as-prepared and irradiated samples has been estimated using Debye-Scherrer equation. Average crystallite sizes obtained for samples S1, $\mathrm{S} 2$, and $\mathrm{S} 3$ are $26 \mathrm{~nm}, 23.4 \mathrm{~nm}$, and $24.5 \mathrm{~nm}$, respectively. The average crystallite size of sample S2 was decreased from $26 \mathrm{~nm}$ to $23.4 \mathrm{~nm}$ due to EB irradiation ( $5 \mathrm{kGy}$ ). However, the size of sample S3 was decreased only up to $24.5 \mathrm{~nm}$ after a dose of $10 \mathrm{kGy}$ irradiation. The principal " $d$ " values taken from the JCPDS file no. 80-0135 for $\mathrm{MnWO}_{4}$ are in close agreement with the observed " $d$ " values. The XRD results showed that crystallite size and percentage of crystallinity decreased after irradiation. It confirms amorphization of the sample due to irradiation which is responsible for the change in optical properties. The results show that average particle size decreases with the EB irradiation dose and suggest the possible control of the size and the density of the $\mathrm{MnWO}_{4}$ nanoparticles by EB irradiation.

All XRD patterns of $\mathrm{MnWO}_{4}$ samples correspond to a wolframite-type monoclinic structure, which is in agreement with the respective Inorganic Crystal Structure Database (ICSD) no. 67907. Unit cell parameters were $a=0.4787 \mathrm{~nm}$, $b=0.5809 \mathrm{~nm}, c=0.4999 \mathrm{~nm}$, and $\beta=91.19^{\circ}$ for sample $\mathrm{S} 1, a=0.4843 \mathrm{~nm}, b=0.5869 \mathrm{~nm}, c=0.5035 \mathrm{~nm}$, and $\beta=91.23^{\circ}$ for sample S2, and $a=0.4823 \mathrm{~nm}, b=0.5826 \mathrm{~nm}$, $c=0.5021 \mathrm{~nm}$, and $\beta=91.22^{\circ}$ for sample S3. All samples showed lattice parameters slightly larger than the calculated and experimental values of the bulk samples reported in the literature $[14,15]$. This deviation might occur due to small particle size of the samples [16].

TEM was used to further examine the particle size, crystallinity, and morphology of $\mathrm{MnWO}_{4}$ samples. TEM bright field images of $\mathrm{MnWO}_{4}$ nanoparticles (calcined at $450^{\circ} \mathrm{C}$ ) are shown in Figure 3. It can be noted from the TEM image (Figure 3) that the particles are agglomerated and exhibit bar-like shape. Selected area electron diffraction (SAED) is shown in the inset of Figure 3, which clearly indicates that the $\mathrm{MnWO}_{4}$ nanoparticles were highly crystalline in nature. As can be seen from the TEM image, the average particle size

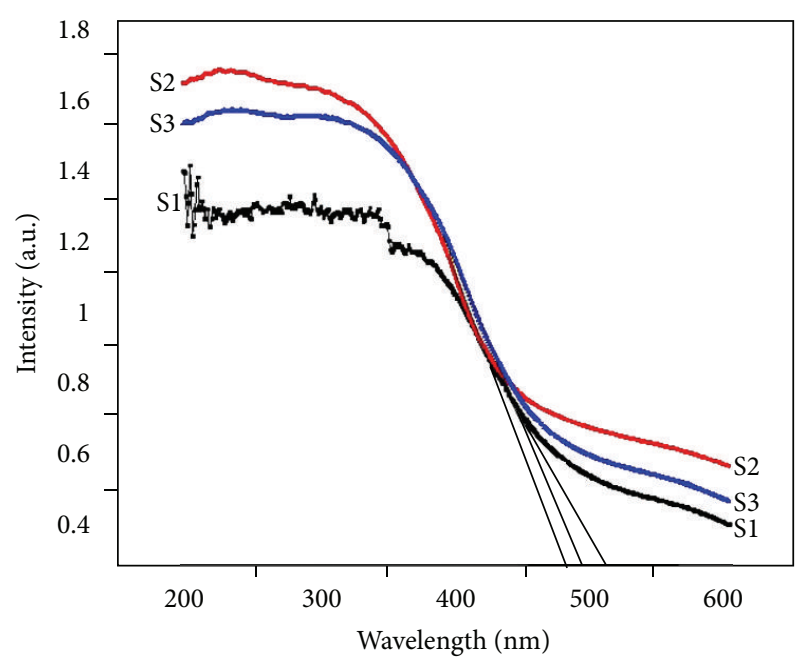

Figure 4: UV-Visible absorption spectra of $\mathrm{MnWO}_{4}$ samples.

is about $26 \mathrm{~nm}$, which is in agreement with the crystallite size obtained from XRD data.

Figure 4 shows the UV-Visible absorbance spectra of pure and irradiated samples of $\mathrm{MnWO}_{4}$ nanoparticles. From the results, it can be observed that the absorption peak of samples S2 and S3 shifts towards the shorter wave length region. This blue shift in the absorption peak is the first-hand signature of significant size reduction of the nanoparticles resulting from EB irradiation. The blue shift in the absorption peak of sample S3 is less as compared to sample S2. It indicates that the size and size distribution of the particle increase beyond a certain EB irradiation dose level.

The optical band gap values obtained from the absorption graphs for samples S1, S2, and S3 were $2.43 \mathrm{eV}, 2.58 \mathrm{eV}$, and $2.51 \mathrm{eV}$, respectively. It is seen that the band gap of $\mathrm{MnWO}_{4}$ nanoparticles shifted from 2.43 to $2.58 \mathrm{eV}$ as particle size reduced from 26 to $23.4 \mathrm{~nm}$ and from 2.43 to $2.51 \mathrm{eV}$ as 
TABLE 1: Comparison of experimental band gap values of $\mathrm{MnWO}_{4}$ with literature values.

\begin{tabular}{lcc}
\hline Eg $(\mathrm{eV})$ & Eg $(\mathrm{eV})$ & Eg $(\mathrm{eV})$ \\
Present work & Experimental & Theoretical \\
\hline $2.43(\mathrm{~S} 1)$ & $2.5[18,19]$ & $1.83[14]$ \\
$2.58(\mathrm{~S} 2)$ & $2.37[14]$ & \\
$2.51(\mathrm{~S} 3)$ & & \\
\hline
\end{tabular}

size reduced from 26 to $24.5 \mathrm{~nm}$. This increase in the band gap might occur due to surface band bending with size reduction of the nanoparticles resulting from EB irradiation [16]. An additional advantage of size reduction is that the large surface area to volume ratio makes possible timely utilization of photo-generated carriers in interfacial processes [17]. Moreover, beam irradiation appeared to improve the optical absorption performance of $\mathrm{MnWO}_{4}$ nanoparticles. In addition, both pure and irradiated samples are useful for photocatalytic activities because their band gap energy values are comparable to the energy of visible or UV light photons.

Table 1 compares present experimental band gap values of $\mathrm{MnWO}_{4}$ with experimental and calculated values reported in the literature $[14,18,19]$. The present experimental values are higher as compared to literature values, which can be attributed to the reduction in particle size of the samples.

Photoluminescence studies provide information relating to different energy states available between valence band and conduction band responsible for radiative recombination. Luminescence spectrum of $\mathrm{MnWO}_{4}$ nanoparticles with $293 \mathrm{~nm}$ excitation is shown in Figure 5. The PL emission spectra of the nonirradiated sample show emission bands at $423,447,460,485$, and $529 \mathrm{~nm}$. These emission bands are attributed to the transition from the ${ }^{1} \mathrm{~A}_{1}$ ground state to the high vibration level of ${ }^{1} \mathrm{~T}_{2}$ and from the low vibration level of ${ }^{1} \mathrm{~T}_{2}$ to the ${ }^{1} \mathrm{~A}_{1}$ ground state within the tetragonal $\mathrm{WO}_{4}{ }^{2-}$ groups [20, 21].

The pure and irradiated samples of $\mathrm{MnWO}_{4}$ could exhibit obvious PL signal with similar curve shapes (Figure 5). The PL spectra of irradiated samples were shown to have larger intensities relative to nonirradiated sample, which was thought to arise from defects and particle size variation [22]. Intermediate energy levels are formed with favourable characteristics due to EB irradiation, which are necessary for recombination process (electron/hole), responsible for the improvement of the PL emission at room temperature. During the excitation process, medium range defects in the monoclinic lattice caused by distortion of octahedral $\left[\mathrm{WO}_{6}\right]$ clusters are responsible for the PL emission. Initially, some electrons from lower intermediate energy levels (oxygen$2 p$ levels) near the valence band absorb the photon energy $(h v)$ at this wavelength $(\lambda=293 \mathrm{~nm})$ and these energetic electrons are promoted to higher intermediate energy levels (tungsten-5d levels) located near the conduction band [21]. The energies generating from the deexcitation process are converted to photons $\left(h v^{1}\right)$. Several photons originating from the participation of different energy states during the electronic transitions are responsible for the intense PL emission.

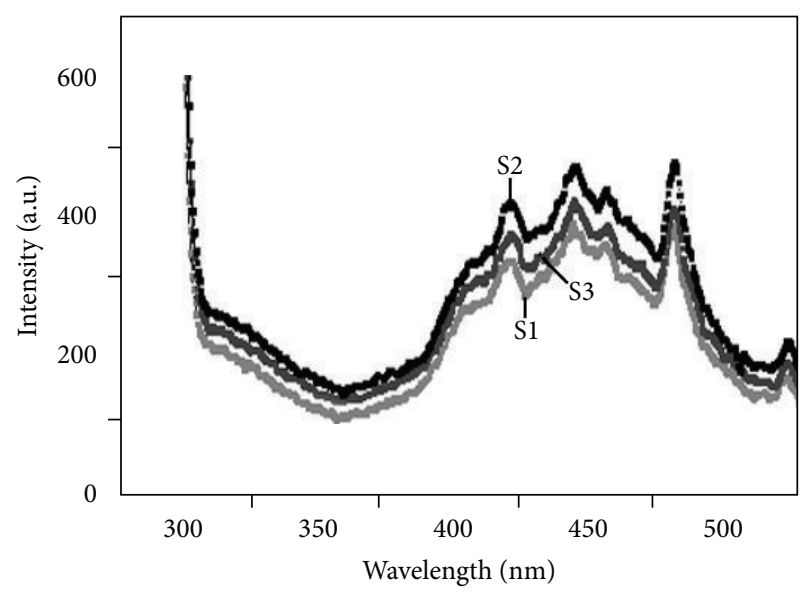

Figure 5: Room temperature PL spectra of $\mathrm{MnWO}_{4}$ samples.

There was a small blue shift for PL spectra of the EB irradiated samples S2 and S3 (Figure 5). The blue shift of band gap with size reduction could be due to surface band bending with surface structural modifications [16]. It can also be seen that PL spectra of the irradiated samples S2 and S3 were broadened. This broadening of $\mathrm{MnWO}_{4}$ nanoparticles might originate from the surface band bending and lattice expansion with particle size reduction caused by the EB irradiation [16].

It can be seen in Figure 5 that the PL intensity increases initially up to $5 \mathrm{kGy}$ dose and then falls off at higher doses of irradiation. The initial increase is attributed to the increase in the trap states that give raise to the luminescence. The increase in PL intensity for an irradiated sample is attributed to the recombination of self-trapped excitons, which is a combined effect of defect centers generated by oxygen vacancies, small particle size, and increased absorption over the UV and visible range [21, 22]. The increase in PL intensity is also an indication of higher photocatalytic activity.

When the EB irradiation dose rate is increased above a certain dose level, the particles agglomerate, thereby reducing the number of fluorophores. This possibly leads to a reduction in the fluorescence intensity (sample S3, Figure 5). Further increase in the irradiation dose appears to have less effect on the trap states but slowly changes the size of the particle, thereby causing a shift in the fluorescence edge to longer wavelength side.

Raman spectra for $\mathrm{MnWO}_{4}$ nanoparticles of pure and irradiated samples are shown in Figure 6. All the eighteen Raman modes were observed in the range $50-1200 \mathrm{~cm}^{-1}$ at room temperature. The most intense band observed at $886 \mathrm{~cm}^{-1}$ originated from the symmetric stretching vibration of a short terminal $\mathrm{W}-\mathrm{O}$ bond, while the asymmetric stretching vibration of a short terminal $\mathrm{W}-\mathrm{O}$ bond appeared at $775 \mathrm{~cm}^{-1}$. Other bands are contributed by asymmetric stretching vibration modes of longer $\mathrm{W}-\mathrm{O}$ bond, symmetric stretching vibrations of longer $\mathrm{W}-\mathrm{O}$ bond, deformation vibration of short $\mathrm{W}-\mathrm{O}$ bonds, vibration modes of $\mathrm{Mn}-\mathrm{O}$, and interchain deformation modes and lattice modes $[16,23,24]$. It can be observed that Raman peaks were slightly shifted for 


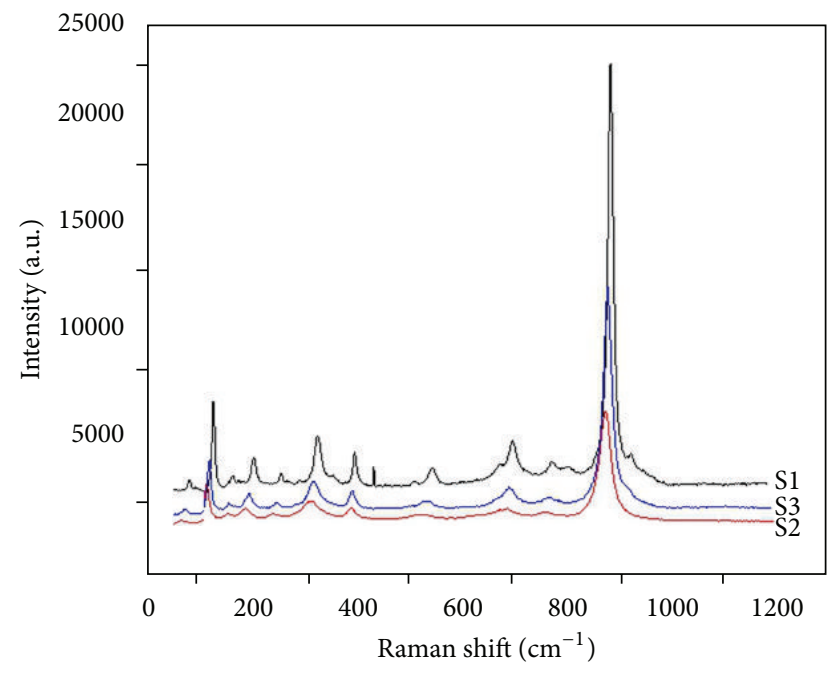

Figure 6: Raman spectra of $\mathrm{MnWO}_{4}$ samples.

the irradiated samples S2 and S3, and the shift was found large for the sample S2.

It can be seen in Figure 6 that Raman peaks of samples S2 and S3 were extremely broadened. The vibration mode for sample S2 at $886 \mathrm{~cm}^{-1}$ broadened from 15.5 to $30.2 \mathrm{~cm}^{-1}$, while for the sample S3, the line width broadened from 15.5 to $23.49 \mathrm{~cm}^{-1}$. The broadened Raman bands could be due to the quantum confinement effect [18]. Besides the quantum confinement, lattice expansion may also contribute to the broadened Raman peaks. The increased lattice volume for $\mathrm{MnWO}_{4}$ nanocrystals at smaller particle sizes would give the enlarged average length of $\mathrm{W}-\mathrm{O}$ bonds, which may decrease the force constant of the $\mathrm{W}-\mathrm{O}$ bond $[25,26]$. As a result, Raman peaks of $\mathrm{MnWO}_{4}$ nanoparticles became broadened as particle size reduced.

Present experimental Raman modes of $\mathrm{MnWO}_{4}$ nanoparticles are presented in Table 2 along with previous experimental and calculated values [23, 27]. Present results are slightly higher than the reported values, and this variation could be caused by the nanoscale size of the samples.

The structural characterization and optical studies of $\mathrm{MnWO}_{4}$ nanoparticles confirm the size reduction and structural modifications caused by the EB irradiation, which in turn result in blue shift in the absorption and PL spectra, and enhanced and broadened PL as well as Raman spectra.

\section{Conclusions}

$\mathrm{MnWO}_{4}$ nanoparticles were synthesized by simple chemical precipitation method, and the effect of high energy EB irradiation on their optical properties was studied in order to improve the optical absorption performance and photoactivity. The EB irradiation may have resulted in size reduction, which in turn caused an increase of the optical band gap as well as photoluminescence intensity and broadening of Raman bands. Furthermore, the data obtained here would seem to show that the method of EB irradiation may be considered as efficient means to enhance the optical response
TABLE 2: Comparison of Raman modes of $\mathrm{MnWO}_{4}$ with the literature.

\begin{tabular}{|c|c|c|c|c|c|}
\hline \multirow{2}{*}{ Mode } & \multicolumn{3}{|c|}{ Present values } & \multirow{2}{*}{$\begin{array}{l}\text { Literature values } \\
{[23,27]}\end{array}$} & \multirow{2}{*}{$\begin{array}{l}\text { Calculated } \\
\text { values }[23,27]\end{array}$} \\
\hline & S1 & S2 & S3 & & \\
\hline $\mathrm{B}_{\mathrm{g}}$ & 90 & 79 & 82 & 89 & 95 \\
\hline$A_{g}$ & 130 & 119 & 123 & 129 & 129 \\
\hline $\mathrm{B}_{\mathrm{g}}$ & 162 & 151 & 154 & 160 & 165 \\
\hline $\mathrm{B}_{\mathrm{g}}$ & 168 & 157 & 161 & 166 & 171 \\
\hline $\mathrm{B}_{\mathrm{g}}$ & 182 & 171 & 174 & 177 & 183 \\
\hline$A_{g}$ & 205 & 193 & 198 & 206 & 226 \\
\hline $\mathrm{B}_{\mathrm{g}}$ & 276 & 265 & 269 & 272 & 278 \\
\hline$A_{g}$ & 259 & 242 & 252 & 258 & 264 \\
\hline $\mathrm{B}_{\mathrm{g}}$ & 297 & 290 & 293 & 294 & 296 \\
\hline $\mathrm{A}_{\mathrm{g}}$ & 330 & 317 & 320 & 327 & 338 \\
\hline $\mathrm{B}_{\mathrm{g}}^{\prime}$ & 361 & 349 & 354 & 356 & 373 \\
\hline$A_{g}^{*}$ & 399 & 393 & 395 & 397 & 389 \\
\hline$B_{g}$ & 514 & 506 & 508 & 512 & 509 \\
\hline$A_{g}^{*}$ & 547 & 528 & 535 & 545 & 548 \\
\hline $\mathrm{B}_{\mathrm{g}}^{*}$ & 675 & 633 & 642 & 674 & 662 \\
\hline $\mathrm{A}_{\mathrm{g}}^{*}$ & 702 & 688 & 695 & 698 & 694 \\
\hline $\mathrm{B}_{\mathrm{g}}^{*}$ & 776 & 762 & 769 & 774 & 775 \\
\hline $\mathrm{A}_{\mathrm{g}}^{*}$ & 888 & 878 & 882 & 885 & 858 \\
\hline
\end{tabular}

and photoactivity of $\mathrm{MnWO}_{4}$ nanoparticles for varied applications.

\section{Acknowledgments}

The authors acknowledge their thanks to Microtron Centre, Mangalore University, Mangalore, and Nirmala College, Muvattupuzha, for providing the opportunity to undertake this study. The financial support from the KSCSTE, Thiruvananthapuram, is gratefully acknowledged.

\section{References}

[1] Y. Xing, S. Song, J. Feng, Y. Lei, M. Li, and H. Zhang, "Microemulsion-mediated solvothermal synthesis and photoluminescent property of 3D flowerlike $\mathrm{MnWO}_{4}$ micro/nanocomposite structure," Solid State Sciences, vol. 10, no. 10, pp. 1299-1304, 2008.

[2] S. Lei, K. Tang, Z. Fang, Y. Huang, and H. Zheng, "Synthesis of $\mathrm{MnWO}_{4}$ nanofibres by a surfactant-assisted complexationprecipitation approach and control of morphology," Nanotechnology, vol. 16, no. 10, pp. 2407-2411, 2005.

[3] D. Errandonea and F. J. Manjón, "Pressure effects on the structural and electronic properties of ABX4 scintillating crystals," Progress in Materials Science, vol. 53, no. 4, pp. 711-773, 2008.

[4] W. Qu, W. Wlodarski, and J. U. Meyer, "Comparative study on micromorphology and humidity sensitive properties of thinfilm and thick-film humidity sensors based on semiconducting $\mathrm{MnWO}_{4}$," Sensors and Actuators B, vol. 64, no. 1-3, pp. 76-82, 2000 . 
[5] A. M. E. S. Raj, C. Mallika, O. M. Sreedharan, and K. S. Nagaraja, "Manganese oxide-manganese tungstate composite humidity sensors," Materials Letters, vol. 53, no. 4-5, pp. 316-320, 2002.

[6] O. Heyer, N. Hollmann, I. Klassen et al., "A new multiferroic material: $\mathrm{MnWO}_{4}$, Journal of Physics Condensed Matter, vol. 18, no. 39, pp. L471-L475, 2006.

[7] S. J. Chen, X. T. Chen, Z. Xue et al., "Morphology control of $\mathrm{MnWO}_{4}$ nanocrystals by a solvothermal route," Journal of Materials Chemistry, vol. 13, no. 5, pp. 1132-1135, 2003.

[8] S. M. Montemayor and A. F. Fuentes, "Electrochemical characteristics of lithium insertion in several 3D metal tungstates $\left(\mathrm{MWO}_{4}, \mathrm{M}=\mathrm{Mn}, \mathrm{Co}, \mathrm{Ni}\right.$ and $\left.\mathrm{Cu}\right)$ prepared by aqueous reactions," Ceramics International, vol. 30, no. 3, pp. 393-400, 2004.

[9] T. Varghese and K. M. Balakrishna, Nanotechnology: An Introduction to Synthesis, Properties and Applications, Atlantic Publishers, New Delhi, India, 2011.

[10] H. Zhou, Y. Yiu, M. C. Aronson, and S. S. Wong, "Ambient template synthesis of multiferroic $\mathrm{MnWO}_{4}$ nanowires and nanowire arrays," Journal of Solid State Chemistry, vol. 181, no. 7, pp. 1539-1545, 2008.

[11] P. Parhi, T. N. Karthik, and V. Manivannan, "Synthesis and characterization of metal tungstates by novel solid-state metathetic approach," Journal of Alloys and Compounds, vol. 465, no. 1-2, pp. 380-386, 2008.

[12] S. Joseph, K. P. Priyanka, T. Smitha, O. P. Jaseentha, E. M. Mohammed, and T. Varghese, "Dielectric studies of nanocrystalline manganese tungstate," in Advanced Nanomaterials for Industrial Applications, V. Rajendran, P. Paramasivam, and Geckeler, Eds., Bloomsbury Publishing, New Delhi, India, 2012.

[13] W. F. Zhang, M. S. Zhang, Z. Yin, and Q. Chen, "Photoluminescence in anatase titanium dioxide nanocrystals," Applied Physics $B$, vol. 70, no. 2, pp. 261-265, 2000.

[14] J. Ruiz-Fuertes, S. López-Moreno, J. Lopez-Solano et al., "Pressure effects on the electronic and optical properties of $\mathrm{AWO}_{4}$ wolframites $(\mathrm{A}=\mathrm{Cd}, \mathrm{Mg}, \mathrm{Mn}$, and $\mathrm{Zn})$ : the distinctive behavior of multiferroic $\mathrm{MnWO}_{4}$, Physical Review B, vol. 86, no. 12, Article ID 125202, 9 pages, 2012.

[15] J. Ruiz-Fuertes, S. López-Moreno, D. Errandonea et al., "Highpressure phase transitions and compressibility of wolframitetype tungstates," Journal of Applied Physics, vol. 107, no. 8, Article ID 083506, 10 pages, 2010.

[16] W. Tong, L. Li, W. Hu, T. Yan, X. Guan, and G. Li, "Kinetic control of $\mathrm{MnWO}_{4}$ nanoparticles for tailored structural properties," Journal of Physical Chemistry C, vol. 114, no. 36, pp. 15298-15305, 2010.

[17] C. M. Mo, L. Zhang, and G. Wang, "Characteristics of dielectric behavior in nanostructured materials," Nanostructured Materials, vol. 6, no. 5-8, pp. 823-826, 1995.

[18] R. Lacomba-Perales, D. Errandonea, A. Segura et al., "A combined high-pressure experimental and theoretical study of the electronic band-structure of scheelite-type $\mathrm{AWO}_{4}(\mathrm{~A}=\mathrm{Ca}, \mathrm{Sr}$, $\mathrm{Ba}, \mathrm{Pb}$ ) compounds," Journal of Applied Physics, vol. 110, no. 4, Article ID 043703, 8 pages, 2011.

[19] A. Mujica, A. Rubio, A. Muñoz, and R. J. Needs, "High-pressure phases of group-IV, III-V, and II-VI compounds," Reviews of Modern Physics, vol. 75, no. 3, pp. 863-912, 2003.

[20] F. Zhang, Y. Yiu, M. C. Aronson, and S. S. Wong, "Exploring the room-temperature synthesis and properties of multifunctional doped tungstate nanorods," Journal of Physical Chemistry C, vol. 112, no. 38, pp. 14816-14824, 2008.
[21] M. A. P. Almeida, L. S. Cavalcante, M. S. Li, J. A. Varela, and E. Longo, "Structural refinement and photoluminescence properties of $\mathrm{MnWO}_{4}$ nanorods obtained by microwave-hydrothermal synthesis," Journal of Inorganic and Organometallic Polymers and Materials, vol. 22, no. 1, pp. 264-271, 2012.

[22] S. K. Gupta, R. Desai, P. K. Jha, S. Sahoo, and D. Kirin, "Titanium dioxide synthesized using titanium chloride: size effect study using Raman spectroscopy and photoluminescence," Journal of Raman Spectroscopy, vol. 41, no. 3, pp. 350$355,2010$.

[23] M. N. Iliev, M. M. Gospodinov, and A. P. Litvinchuk, "Raman spectroscopy of $\mathrm{MnWO}_{4}$," Physical Review B, vol. 80, no. 21, Article ID 212302, 4 pages, 2009.

[24] L. H. Hoang, N. T. M. Hien, W. S. Choi et al., "Temperaturedependent Raman scattering study of multiferroic $\mathrm{MnWO}_{4}$," Journal of Raman Spectroscopy, vol. 41, no. 9, pp. 1005-1010, 2010.

[25] G. Gouadec and P. Colomban, "Raman Spectroscopy of nanomaterials: How spectra relate to disorder, particle size and mechanical properties," Progress in Crystal Growth and Characterization of Materials, vol. 53, no. 1, pp. 1-56, 2007.

[26] G. Gouadec and P. Colomban, "Raman spectroscopy of nanostructures and nanosized materials," Journal of Raman Spectroscopy, vol. 38, no. 6, pp. 598-603, 2007.

[27] J. Ruiz-Fuertes, D. Errandonea, S. López-Moreno et al., "Highpressure Raman spectroscopy and lattice-dynamics calculations on scintillating $\mathrm{MgWO}_{4}$ : comparison with isomorphic compounds," Physical Review B, vol. 83, no. 21, Article ID 214112, 11 pages, 2011. 

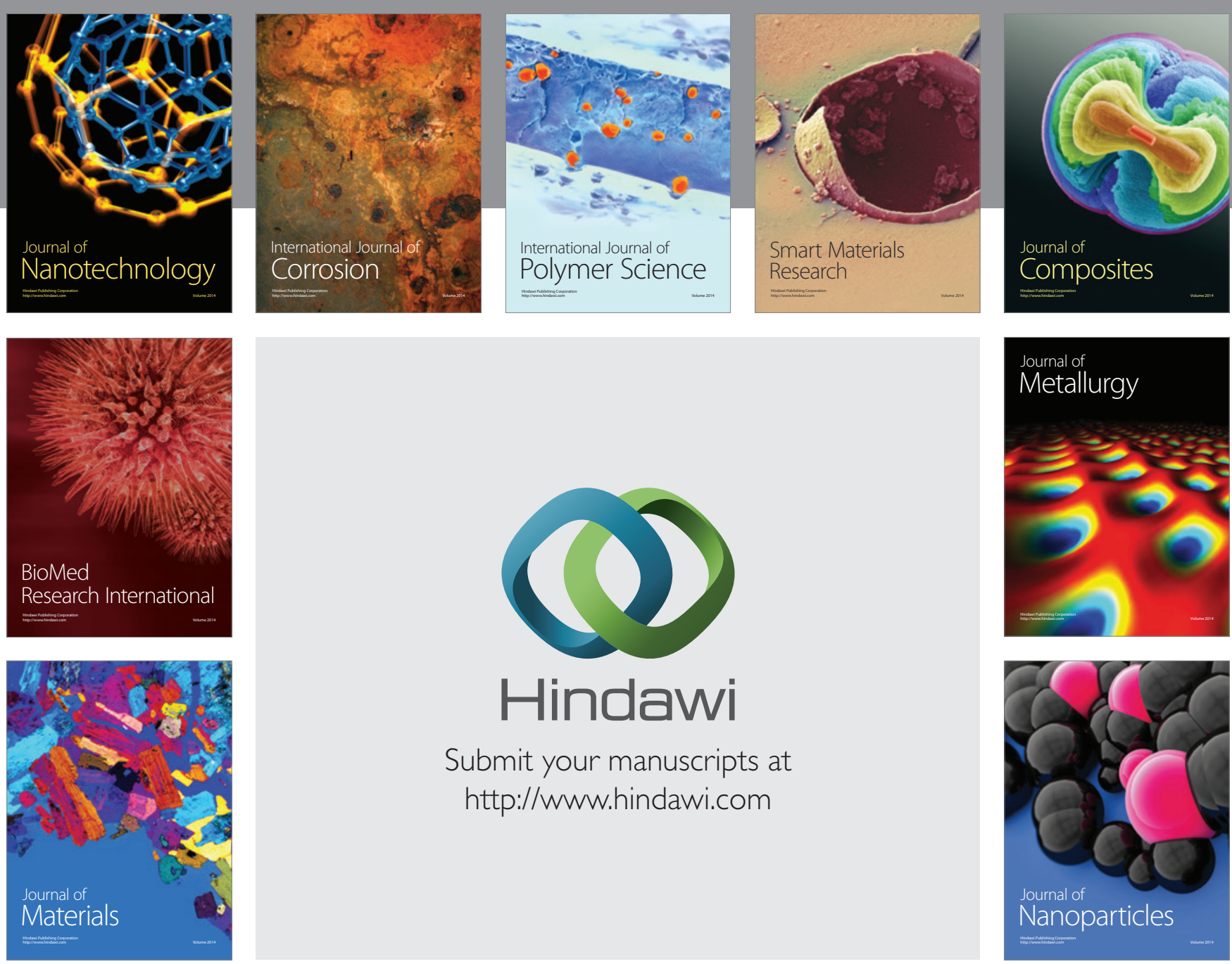

Submit your manuscripts at http://www.hindawi.com
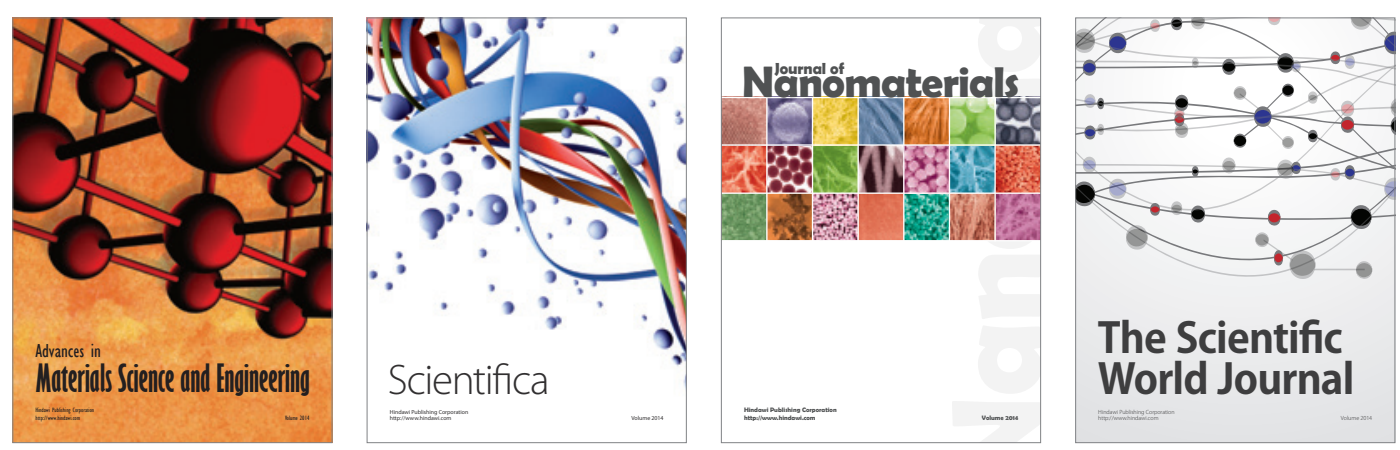

\section{The Scientific World Journal}
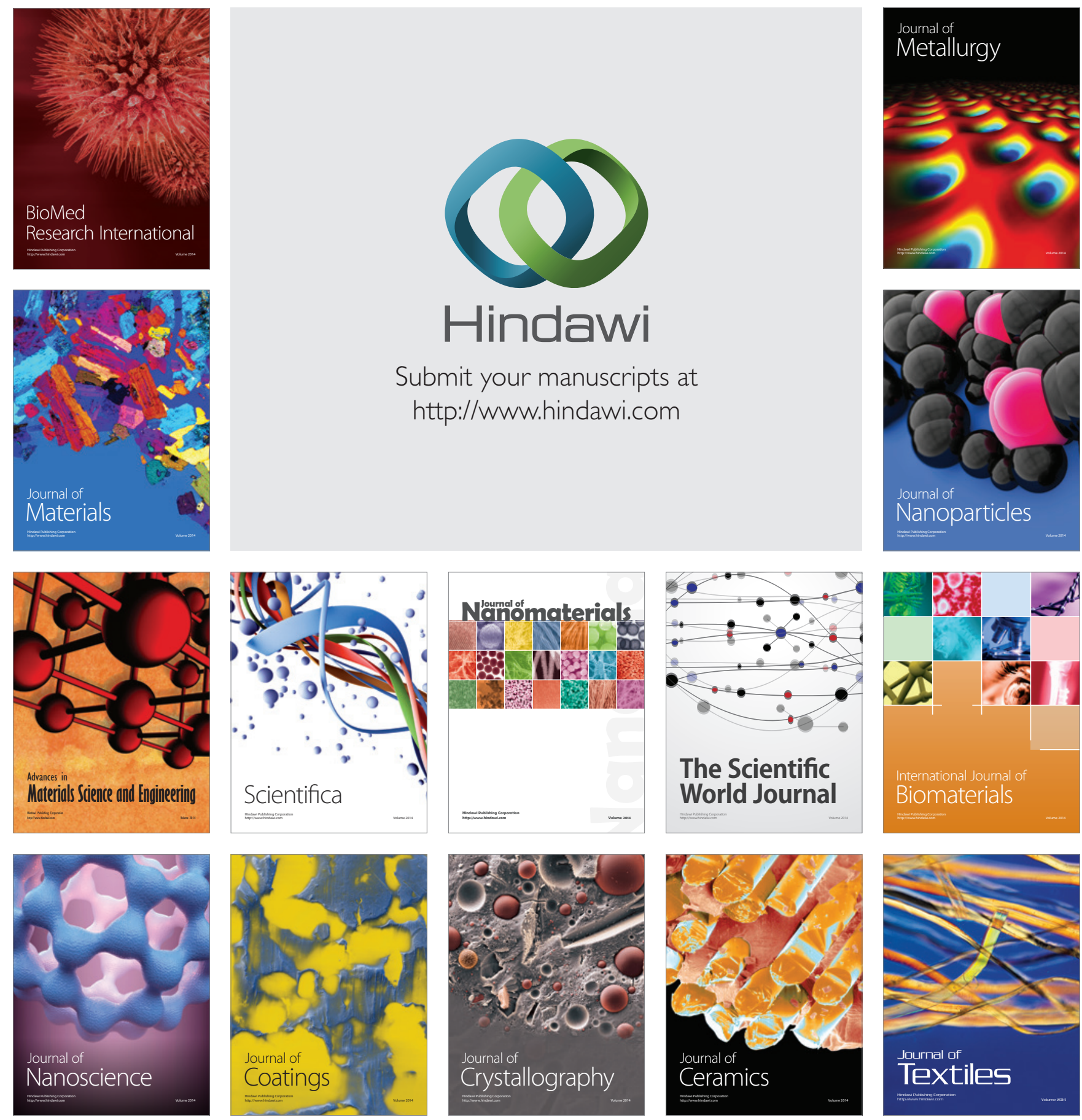